\title{
Assessment of China's virtual air pollution transport embodied in trade by using a consumption-based emission inventory
}

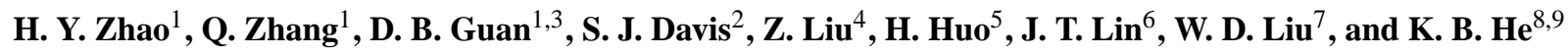 \\ ${ }^{1}$ Ministry of Education Key Laboratory for Earth System Modeling, Center for Earth System Science, Tsinghua University, \\ Beijing, China \\ ${ }^{2}$ Department of Earth System Science, University of California, Irvine, Irvine, CA, USA \\ ${ }^{3}$ Center for Climate Change Economics and Policy, School of Earth and Environment, University of Leeds, \\ Leeds LS2 9JT, UK \\ ${ }^{4}$ Sustainability Science Program and Energy Technology Innovation Policy Project, Kennedy School of Government, Harvard \\ University, Cambridge, MA, USA \\ ${ }^{5}$ Institute of Energy, Environment and Economy, Tsinghua University, Beijing, China \\ ${ }^{6}$ Laboratory for Climate and Ocean-Atmosphere Studies, Department of Atmospheric and Oceanic Sciences, School of \\ Physics, Peking University, Beijing, China \\ ${ }^{7}$ Institute of Geographic Sciences and Natural Resources Research, Chinese Academy of Sciences, Beijing, China \\ ${ }^{8}$ State Key Joint Laboratory of Environment Simulation and Pollution Control, School of Environment, Tsinghua University, \\ Beijing, China \\ ${ }^{9}$ State Environmental Protection Key Laboratory of Sources and Control of Air Pollution Complex, Beijing, China
}

Correspondence to: Q. Zhang (qiangzhang @ tsinghua.edu.cn)

Received: 24 July 2014 - Published in Atmos. Chem. Phys. Discuss.: 10 October 2014

Revised: 31 March 2015 - Accepted: 12 April 2015 - Published: 19 May 2015

\begin{abstract}
Substantial anthropogenic emissions from China have resulted in serious air pollution, and this has generated considerable academic and public concern. The physical transport of air pollutants in the atmosphere has been extensively investigated; however, understanding the mechanisms how the pollutant was transferred through economic and trade activities remains a challenge. For the first time, we quantified and tracked China's air pollutant emission flows embodied in interprovincial trade, using a multiregional input-output model framework. Trade relative emissions for four key air pollutants (primary fine particle matter, sulfur dioxide, nitrogen oxides and non-methane volatile organic compounds) were assessed for 2007 in each Chinese province. We found that emissions were significantly redistributed among provinces owing to interprovincial trade. Large amounts of emissions were embodied in the imports of eastern regions from northern and central regions, and these were determined by differences in regional economic status and environmental policy. It is suggested that measures should be introduced to reduce air pollution by integrat-
\end{abstract}

ing cross-regional consumers and producers within national agreements to encourage efficiency improvement in the supply chain and optimize consumption structure internationally. The consumption-based air pollutant emission inventory developed in this work can be further used to attribute pollution to various economic activities and final demand types with the aid of air quality models.

\section{Introduction}

China's rapid industrialization since 2000 has been accompanied by large increases in emissions of air pollutants, such as sulfur dioxide $\left(\mathrm{SO}_{2}\right)$, nitrogen oxides $\left(\mathrm{NO}_{x}\right)$, carbon monoxide $(\mathrm{CO})$, non-methane volatile organic compounds (NMVOC) and black carbon (BC) (Ohara et al., 2007; Lin et al., 2010; Zhang et al., 2009). In turn, the visible degradation of air quality in the country has made environmental and health issues a major focus of policy (Yang et al., 2013; Boldo et al., 2006; Bell et al., 2007). Ambient partic- 
ulate matter is considered the most substantial health risk in China, having contributed to 1.2 million premature deaths and removing 25 million healthy life years in 2010 alone (Yang et al., 2013). Related economic costs are also enormous: the human health impacts of $\mathrm{PM}_{10}$ in urban areas of China were estimated at almost US 74 billion in 2010 (Yu et al., 2013), nearly $1.3 \%$ of the national gross domestic product for that year. In response, China's government announced its Action Plan for Air Pollution Control in September 2013 with the purpose of supporting efforts to reduce air pollution. In this plan, air quality and economic development are of equal importance in assessing the performance of government officials at local, provincial and national levels.

Pollution abatement must begin with an understanding of pollution sources. Previous researches have therefore focused on bottom-up inventories of pollutant emissions over China, based on energy statistics and data sets of technology in use (e.g., Zhang et al., 2007, 2009; Streets et al., 2003; Lei et al., 2011). These inventories assign emissions to where pollutants are physically produced, which results in production-based pollution accounting. These inventories have been extensively used in chemical transport models to predict and interpret air pollution or used to guide implementation of emission control measures.

As part of efforts to improve air quality, the Chinese government has imposed strict regulations on pollutant emissions in mega-cities and developed regions. However, if the response is to shift industry out of these regions without changing consumption patterns, the result of the regulations may be an increase in total pollutant emission. This is because there will be an increase of such emissions through transport along geographically extended supply chains and because of generally inefficient production in less-regulated areas. The redistribution of emissions could have potentially significant effects on regional air quality. For example, roughly one-third of electricity consumed in Beijing is generated in Inner Mongolia (Liu et al., 2012a). Stricter regulations of the Beijing power sector will tend to increase the import of electricity if similar actions are not taken in Inner Mongolia. Given this connection, the most cost-effective means of reducing emissions from the Inner Mongolia power sector might not only be deploying new generation technologies there but also energy conservation in Beijing, as well as facilitating technological cooperation between the two regions (Liu et al., 2013; Lindner et al., 2013). In this regard, effective and cost-effective management of air quality may therefore require policies that cover the entire supply chain, which in turn will depend upon quantitative understanding of emission transport between producers and consumers.

Indeed, this dynamic consequence has already been demonstrated for $\mathrm{CO}_{2}$ emissions. High levels of consumption in China's developed coastal regions are driving these emissions in interior provinces, where $\mathrm{CO}_{2}$ emission intensity is much greater (Feng et al., 2013). As a result, substantial emissions are embodied in goods traded between provinces, and less-developed regions bear a disproportionate share of the costs for both pollution and its mitigation. Recent work has demonstrated that the effectiveness of efforts to reduce pollution depend on understanding not only where pollutant is produced but also where goods and services related to the pollution are ultimately consumed (Davis and Caldeira, 2010; Davis et al., 2011; Feng et al., 2013; López et al., 2014; Guan et al., 2014a). Lin et al. (2014) demonstrated that China's international trade has a significant impact on global air quality by linking the input-output model with the emission inventory and air quality model. However, the transport of air pollutant emissions through economic and trade activities among various regions of the country are not well established.

In this study, we developed a consumption-based air pollutant emission inventory framework at provincial scale to explore emission flows embodied in supply chains of China. With this framework, we estimated emissions of four air pollutants (primary fine particular matters $\left(\mathrm{PM}_{2.5}\right)$ and its key precursors $\mathrm{SO}_{2}, \mathrm{NO}_{x}$ and NMVOC) embodied in goods and services traded between 30 provinces or municipalities in China for 2007. We used a multiregional inputoutput (MRIO) model to reallocate emissions from producing provinces to provinces where the related products were ultimately consumed. Given China's substantial international trade, a sizable proportion of pollutant is related to goods ultimately consumed in other countries. We allocated such emissions to a single "out-of-China" region. To better assess consumption patterns, we also examined contribution of four consumption categories: urban household, rural household, government and capital formation. The consumptionbased air pollutant emission inventory developed herein can be used to attribute pollution to various economic sectors and final demand types with the aid of air quality models. It should be noted that our consumption-based accounting procedure should not be interpreted as assigning all economic or ethical responsibility for pollution to consumers (Wiedmann, 2009; Davis and Caldeira, 2010; Guan et al., 2014a); it represents a critical source of information for consideration by decision makers, who would design public policy accordingly.

This paper is organized as follows. In Sect. 2, we describe key principles of consumption-based accounting and details of our MRIO model, including sources and treatment of raw economic data. Section 3 presents consumption-based emissions at provincial level and pollutant emissions embodied in traded products. Section 4 address possible impacts of current policies according to our findings and related policy implication. 


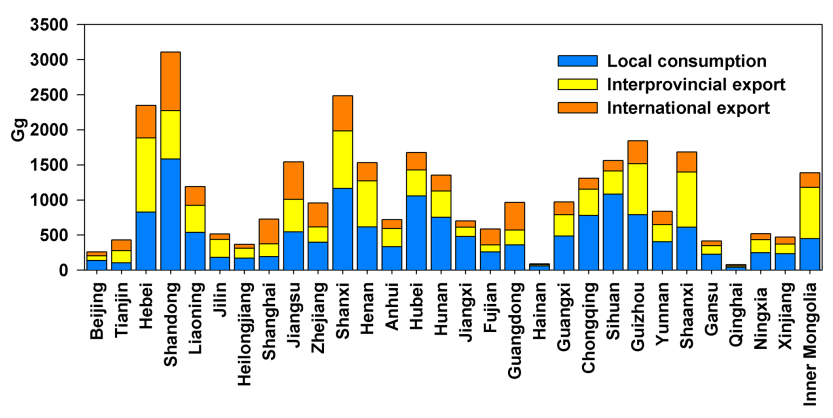

Figure 1. Production-based $\mathrm{SO}_{2}$ emissions in 2007 by province and consumption locations.

\section{Methodology and data}

\subsection{MRIO analysis}

Since its development by Leontief (1970), environmental extended input-output analysis has been widely used to analyze drivers and causes of global and regional environmental change in many different contexts (Wiedmann et al., 2007; Hertwich and Peters, 2009; Minx et al., 2009; Suh, 2009; Guan and Barker, 2012). In the past several years, environmental extended MRIO models have been developed to quantify global $\mathrm{CO}_{2}$ emissions embodied in international trade, initially for a specific year (Davis and Caldeira, 2010; Feng et al., 2012) and later for multiple years (Peters et al., 2011). More recently, sectoral resolution of an input-output table was improved to facilitate MRIO analysis among 187 countries and 15909 sectors (Lenzen et al., 2012, 2013). Liu et al. (2012) developed an MRIO model consisting of 30 sectors and 30 provinces in China, which has been widely used to assess $\mathrm{CO}_{2}$ emissions embodied in trade flows within China and internationally in 2007 (Feng et al., 2013). Here, we apply this Chinese MRIO in 2007 to quantify non- $\mathrm{CO}_{2}$ air pollutants embodied in goods and service traded among the country's provinces and internationally. We summarize the model and data sources bellow.

The Chinese MRIO framework begins with the accounting balance of monetary flows:

$\boldsymbol{x}^{r}=\mathbf{A}^{r r} \boldsymbol{x}^{r}+\boldsymbol{y}^{r r}+\sum_{s \neq r} \mathbf{A}^{r s} \boldsymbol{x}^{s}+\sum_{s \neq r} \boldsymbol{y}^{r s}+\boldsymbol{y}^{r e}$.

Here, $r$ and $s$ indicate province $r$ (producer) and $s$ (consumer); $\boldsymbol{x}^{r}$ and $\boldsymbol{x}^{s}$ are respective vectors for sectoral total outputs in provinces $r$ and $s ; \mathbf{A}^{r r} x^{r}$ represents industry requirement to produce its regional final products and $\mathbf{A}^{r r}$ is a matrix with columns representing specific sectors' local input required to produce one unit output; $\mathbf{A}^{r s} x^{s}$ and $\mathbf{A}^{r s}$ represent the cross-regional industry requirement import from province $r$ to $s$ and its coefficients to produce one unit output; $\boldsymbol{y}^{r r}$ is a vector with its elements representing final consumption (urban and rural household, government and capital formation) produced locally; $\boldsymbol{y}^{r s}$ is the cross-regional final prod- uct supply from province $r$ to $s$; and $\boldsymbol{y}^{r e}$ is a vector indicating region $r^{\prime}$ s sectoral product for international export. Evaluating the equation for all sectors and provinces, we constructed a matrix representing the entire Chinese domestic economy, including its export:

$$
\begin{aligned}
\left(\begin{array}{c}
\boldsymbol{x}^{1} \\
\boldsymbol{x}^{2} \\
\vdots \\
\boldsymbol{x}^{m}
\end{array}\right) & =\left(\begin{array}{cccc}
\mathbf{A}^{11} & \mathbf{A}^{12} & \ldots & \mathbf{A}^{1 m} \\
\mathbf{A}^{21} & \mathbf{A}^{22} & \cdots & \mathbf{A}^{2 m} \\
\vdots & \vdots & \ddots & \vdots \\
\mathbf{A}^{m 1} & \mathbf{A}^{m 2} & \cdots & \mathbf{A}^{m m}
\end{array}\right)\left(\begin{array}{c}
\boldsymbol{x}^{1} \\
\boldsymbol{x}^{2} \\
\vdots \\
\boldsymbol{x}^{m}
\end{array}\right) \\
& +\left(\begin{array}{c}
\sum_{r} \boldsymbol{y}^{1 r}+\boldsymbol{y}^{1 e} \\
\sum_{r}^{r} \boldsymbol{y}^{2 r}+\boldsymbol{y}^{2 e} \\
\vdots \\
\sum_{r} \boldsymbol{y}^{m r}+\boldsymbol{y}^{m e}
\end{array}\right) .
\end{aligned}
$$

Here $m$ indicates the total number of regions, which was 30 in this research.

When solved from total output, Eq. (2) can yield

$\boldsymbol{x}=(\mathbf{I}-\mathbf{A})^{-1} \boldsymbol{y}$.

The bold uppercase and lowercase letters in this equation represent corresponding matrixes and vectors in Eq. (2). $(\mathbf{I}-\mathbf{A})^{-1}$ is the Leontief inverse matrix.

Pollutant emissions (referring here to primary $\mathrm{PM}_{2.5}, \mathrm{SO}_{2}$, $\mathrm{NO}_{x}$ and NMVOC; see Sect. 2.4 below) are then calculated by incorporating a vector of emission intensity:

$e=\hat{\boldsymbol{f}}(\mathbf{I}-\mathbf{A}) \boldsymbol{y}$.

Here, $\hat{f}$ indicates a diagonal matrix with the elements of vector $f$ on its main diagonal and all other entries equal to 0 ; component $\boldsymbol{f}_{i}^{r}$ in $\boldsymbol{f}$ is the direct emission intensity vector calculated by sector $i$ 's total emissions divided by its total output in a given region $r$ (Hubacek and Sun, 2005; Lin et al., 2014; Guan et al., 2014b).

\subsection{Emissions embodied in interprovincial and international trade flows}

Using pollutant emissions calculated by the Chinese MRIO, we quantified the emissions embodied in trade flows between China's provinces and between those provinces and other countries. By disaggregating the final demand of each province in Eq. (4), we quantified emissions of each pollutant embodied in the goods and services consumed in each province as well as where the emissions were produced. For example, the final demand of province $r$ is $\boldsymbol{y}_{c}^{r}=$ $\left(\begin{array}{llllll}\boldsymbol{y}^{1 r} & \boldsymbol{y}^{2 r} & \ldots & \boldsymbol{y}^{r r} & \ldots & \boldsymbol{y}^{m r}\end{array}\right)^{\prime}$, which includes products produced in province $r\left(\boldsymbol{y}^{r r}\right)$ and final products imported from other regions $\left(\sum_{s \neq r} \boldsymbol{y}^{s r}\right)$. Using this vector as $Y$ in Eq. (4) gives emissions embodied in the final consumption of 
province $r$ :

$e_{c}^{r}=\sum_{s=1} e_{c}^{s r}=\sum_{s=1} f^{s}(\mathbf{I}-\mathbf{A})^{-1} \boldsymbol{y}_{c}^{r}$,

where $\boldsymbol{f}^{s}$ is a vector of corresponding sectoral pollution intensities for region $s$ but 0 for all other regions. $e_{c}^{r}$ represents total pollutant emissions embodied in region $r$ 's consumption that were produced within China; it excludes emissions embodied in any interprovincial exports and includes imports $\left(e_{c}^{s r}, r \neq s\right)$. The solution is both region- and sector-specific.

Pollutants embodied in international exports are calculated by isolating the demand $Y$ for exports, $\boldsymbol{y}^{e}$ :

$e^{e}=\sum_{r=1} e^{r e}=\sum_{r=1} f^{r}(\mathbf{I}-\mathbf{A})^{-1} \boldsymbol{y}^{e}$.

Here, $e^{r e}$ indicates province $r$ 's emission embodied in international exports.

This research also estimated emissions embodied in international imports. We began with a simplifying assumption that imported products were produced under the same industrial structure and technology in China (Tang et al., 2012). This gives emissions avoided by import (EAI):

$e_{\mathrm{EAI}}=\sum_{r=1} e_{\mathrm{EAI}}^{r}=\boldsymbol{f}(\mathbf{I}-\mathbf{A})^{-1} y^{I m}$

To obtain the pollutant emissions embodied in each province's imports, we assume that China's total import from nation $i$ was proportionally distributed to each province. Then we adjusted the $e_{\text {EAI }}$ of each province by a coefficient $u_{r}$ that reflects the producing nation's average pollution intensity (Lin et al., 2014):

$\mu_{r}=\sum_{i} \frac{\mathrm{NI}_{i}}{\mathrm{PI}_{r}} \times \frac{N_{i}^{\mathrm{exp}}}{C^{\text {tim }}}$.

$\mathrm{NI}_{i}$ indicates nation $i$ 's pollution intensity; $\mathrm{PI}_{r}$ signifies province $r$ 's pollution intensity; $N_{i}^{\exp }$ indicates nation $i$ 's total export to China; $C^{\text {tim }}$ represents China's total import. Thus, the emissions embodied in international imports to province $r$ is $\mu_{r} e_{\mathrm{EAI}}^{r}$.

Apart from MRIO table, additional databases were used in this study. Trade data between China and other countries used in this section for China's international trade were aggregated from the China Foreign Economic Statistical Yearbook (National Bureau of Statistics, 2008a) and the China Trade and Economic Statistical Yearbook (National Bureau of Statistics, 2008b). Provincial input-output tables (National Bureau of Statistics, 2011) were used to supplement and modify the international import, which is more aggregated in the MRIO table.

\subsection{Consumption-based emissions by province}

Consumption-based emissions represent quantities of pollution related to all goods and services consumed by a given province (Peters, 2008; Peters and Hertwich, 2008; Davis and Caldeira, 2010; Lin et al., 2014; Lindner and Guan 2014). Gross flows of emissions embodied in trade can thus be used to quantify consumption-based emissions by adding emissions embodied in imports to and subtracting emissions embodied in exports from emissions physically produced in each province:

$\mathrm{CE}=\mathrm{PE}-\mathrm{INE}-\mathrm{IPE}+\mathrm{INI}+\mathrm{IPI}$.

$\mathrm{CE}$ and $\mathrm{PE}$ indicate regional pollutant inventories from the consumption and production perspectives, respectively; INE and INI signify emissions embodied in international exports and imports, respectively; IPE and IPI represent emissions embodied in interprovincial exports and imports.

\subsection{Production-based inventory data}

The pollution-intensity vector $\boldsymbol{f}$ in Eqs. (4) and (7) is derived from the multi-resolution emission inventory for China (MEIC: http://www.meicmodel.org) compiled by Tsinghua University. The MEIC is a production-based inventory, updated from the widely used INTEX-B data set (Zhang et al., 2009). The inventory covers 31 provinces or autonomous regions, 10 pollutants (e.g., $\mathrm{SO}_{2}, \mathrm{NO}_{x}, \mathrm{CO}, \mathrm{NMVOC}, \mathrm{BC}$, $\mathrm{PM}_{2.5}, \mathrm{PM}_{10}$, ammonia $\left(\mathrm{NH}_{3}\right)$, organic carbon $(\mathrm{OC})$ and $\mathrm{CO}_{2}$ ) and $\sim 700$ emission source categories. In this study, we used the energy balance table of each province from the China Energy Statistical Yearbook (National Bureau of Statistics, 2008c) and revised sectoral energy consumption from the China Economic Census Yearbook (National Bureau of Statistics, 2010) to map MEIC emission data onto the sectors in our Chinese MRIO (Guan et al., 2014c). The sector classification appears in Table A1 of Appendix A (all $30 \mathrm{sec}$ tors were aggregated into 27 , making for consistency between MRIO and emission sectors). Global emissions were taken from EDGAR v.4.2 (http://edgar.jrc.ec.europa.eu/) to calculate aggregated pollution intensities for other countries (Eq. 8).

\section{Results}

\subsection{Production-based emissions by consumption types}

Provincial production-based air pollutant emissions can be separated into three categories according to their service destinations: local consumption, other regions' consumption within China through interprovincial export and other countries' consumption through international export. On average, we found that emissions from local consumptions contributed 62, 46, 46 and $56 \%$ of national total emissions for primary $\mathrm{PM}_{2.5}, \mathrm{SO}_{2}, \mathrm{NO}_{x}$ and $\mathrm{NMVOC}$, respectively, with large variations between provinces. Higher contributions for primary $\mathrm{PM}_{2.5}$ and NMVOC could be attributed to emissions from direct energy consumption in the residential activity. Regionally, contributions from each category varied 
by provinces, because of their different trade patterns and regional attributes. Figure 1 shows $\mathrm{SO}_{2}$ as an example to demonstrate production-based emissions of 30 provinces and the contribution of each category. The greatest contribution from local consumption was in Sichuan (69\%) and Jiangxi (68\%), indicating strong self-sufficiency in these regions. While lowest such contribution was in eastern coastal areas such as Tianjin $(24 \%)$ and Shanghai $(27 \%)$.

\subsection{Consumption-based emissions by province}

Table 1 compares production-based and consumption-based pollutant emissions in 2007 for all 30 provinces in mainland China. For provinces where service industries and light industries are substantially developed, consumptionbased emissions were greater than production-based ones because the former were very dependent on products or energy imported from other provinces. For example, Beijing's consumption-based emissions were 2.6-, 3-, 1.6- and 1.5fold its consumption-based emissions for primary $\mathrm{PM}_{2.5}$, $\mathrm{SO}_{2}, \mathrm{NO}_{x}$ and NMVOC, respectively; about $74-83 \%$ of its consumption-based emissions were imported. In provinces with economies dependent on energy generation, heavy industry or materials manufacturing, production-based emissions were much greater than consumption-based ones. For example, in Hebei, $63 \%$ of primary $\mathrm{PM}_{2.5}, 67 \%$ of $\mathrm{SO}_{2}$, $68 \%$ of $\mathrm{NO}_{x}$ and $56 \%$ of NMVOC emissions were related to products consumed outside the province. Similarly, consumption-based emissions in Shanxi and Inner Mongolia were $26-62 \%$ less than production-based emissions. This difference indicates that over $50 \%$ of their total pollutant emissions were embodied in producing inter-provincially or internationally exported products. Anhui, Sichuan and Guangxi had similar emissions under these two accounting methods, because substantial proportions of goods produced in these provinces were consumed locally. In these provinces, emissions were largely related to residential direct energy consumption (considered here as the emission service for regional consumption).

According to the input-output analysis, regional final consumption can be divided into four categories: urban households consumption, rural households consumption, government consumption and capital formation. Emissions caused by domestic rural and urban residential direct consumption were listed as independent final categories because they are irrelevant to economic production systems and were designated rural_direct and urban_direct in the research.

Figure 2 presents pollutant emissions caused by each final consumption category among the 30 provinces. Capital formation and urban residential consumption dominated the consumption-based emission of $\mathrm{SO}_{2}$ and $\mathrm{NO}_{x}$ in all provinces, reflecting large-scale nationwide expansion of infrastructure. Among the 30 regions, capital formation in Shandong contributed most to national consumptionbased $\mathrm{SO}_{2}$ (5\% of the national total) and $\mathrm{NO}_{x}(3 \%$ of that total) emissions; this was followed by Jiangsu, Zhejiang and Guangdong. For primary $\mathrm{PM}_{2.5}$ and NMVOC, capital formation and direct rural residential energy consumption dominated total consumption-based emissions in nearly all provinces. In Beijing, Jiangsu, Shanghai, Zhejiang and Guangdong, biomass combustion is not used as a significant energy source, so capital formation and urban residential consumption activities dominated their total consumption-based emissions. For less-developed regions, such as Guangxi, Guizhou, Anhui and Sichuan, biofuel remains an important energy source, so the related combustion emission accounts for over $50 \%$ of regional consumptionbased emissions for primary $\mathrm{PM}_{2.5}$ and NMVOC.

\subsection{Emissions embodied in interprovincial trade flows}

Figure 3 shows the balance of air pollutant emissions embodied in products traded among the 30 provinces in 2007. Nationally, 3.1 Tg of primary $\mathrm{PM}_{2.5}$ (23\% of total Chinese production-based emission), $10.5 \mathrm{Tg}$ of $\mathrm{SO}_{2}$ (33\% of that total), 7.6 $\mathrm{Tg}$ of $\mathrm{NO}_{x}$ (31\% of the total) and $4.7 \mathrm{Tg}$ of NMVOC (23\% of the total) were emitted during the production of products or services that were ultimately consumed in other provinces or regions in the country. Economically advanced regions such as Beijing, Tianjin, Shanghai, Jiangsu, Zhejiang and Guangdong were net importers of emissions, whereas areas of heavy industry or manufacturing bases such as Hebei, Shanxi, Henan, Inner Mongolia and Shaanxi were net emissions exporters.

Emissions embodied in intermediate products make up a large portion of total emissions embodied in interprovincial trade. This indicates that most goods being traded had supply chains covering multiple provinces, with relatively few products entirely manufactured in one province for consumption in the local region, reflecting a strengthened interregional cooperation in manufacturing pattern. For emissions embodied in interprovincial exports, the ratio between finished and intermediate goods varied from $1: 1$ to $1: 12$ across the provinces. The smallest ratio was $1: 12$ for Shanxi, which exported large amounts of energy to Beijing, Tianjin and other regions in southern China. The finished-to-intermediate ratio of emissions embodied in imports was similarly variable, ranging from $1: 1$ to $1: 13$. The smallest ratio was $1: 13$ for Zhejiang, an area that imported large volumes of intermediate products from the central, north and northwest regions to support its local industries.

Figure 4 presents the largest net flows of embodied pollutants among the eight regions (listed in Table A2 of Appendix A). From the perspective of technology development, there was an increasing trend of pollutant intensity from southeast to northwest China for all four pollutants. The northeast had the strongest emission intensities for $\mathrm{SO}_{2}$ (223 Mg 100 million $\left.\mathrm{CNy}^{-1}\right), \quad \mathrm{NO}_{x} \quad\left(145 \mathrm{Mg} 100\right.$ million $\left.\mathrm{CNy}^{-1}\right)$ and NMVOC (74 Mg 100 million $\left.\mathrm{CNy}^{-1}\right)$. Central 
Table 1. Comparison of regional pollutant emissions from production- and consumption-based emissions $\left(\mathrm{Gg}^{\mathrm{year}}{ }^{-1}\right)$.

\begin{tabular}{|c|c|c|c|c|c|c|c|c|}
\hline \multirow{2}{*}{$\begin{array}{l}\text { Pollutant } \\
\text { Region }\end{array}$} & \multicolumn{2}{|c|}{ Primary $\mathrm{PM}_{2.5}$} & \multicolumn{2}{|c|}{$\mathrm{SO}_{2}$} & \multicolumn{2}{|c|}{$\mathrm{NO}_{x}$} & \multicolumn{2}{|c|}{ NMVOC } \\
\hline & Pro & Con & Pro & Con & Pro & Con & Pro & Con \\
\hline Beijing & 111 & 285 & 261 & 775 & 385 & 629 & 372 & 571 \\
\hline Tianjin & 127 & 183 & 429 & 548 & 361 & 445 & 286 & 326 \\
\hline Hebei & 974 & 513 & 2347 & 1387 & 1780 & 1036 & 1199 & 842 \\
\hline Shandong & 1276 & 933 & 3105 & 2375 & 2582 & 1940 & 1948 & 1554 \\
\hline Liaoning & 587 & 416 & 1189 & 826 & 1250 & 850 & 900 & 668 \\
\hline Jilin & 316 & 338 & 513 & 735 & 650 & 723 & 512 & 493 \\
\hline Heilongjiang & 370 & 363 & 367 & 475 & 786 & 640 & 705 & 589 \\
\hline Shanghai & 142 & 338 & 726 & 1112 & 591 & 838 & 557 & 836 \\
\hline Jiangsu & 680 & 689 & 1544 & 1375 & 1777 & 1356 & 1571 & 1339 \\
\hline Zhejiang & 368 & 548 & 957 & 1371 & 1231 & 1291 & 1113 & 1008 \\
\hline Shanxi & 755 & 435 & 2483 & 1241 & 1148 & 593 & 653 & 486 \\
\hline Henan & 1015 & 667 & 1532 & 1157 & 1685 & 1108 & 1176 & 1032 \\
\hline Anhui & 555 & 515 & 718 & 667 & 871 & 674 & 812 & 759 \\
\hline Hubei & 542 & 481 & 1674 & 1248 & 862 & 695 & 768 & 751 \\
\hline Hunan & 544 & 441 & 1353 & 1045 & 730 & 646 & 595 & 556 \\
\hline Jiangxi & 286 & 286 & 701 & 906 & 455 & 589 & 348 & 378 \\
\hline Fujian & 261 & 221 & 586 & 516 & 525 & 453 & 430 & 422 \\
\hline Guangdong & 629 & 669 & 963 & 1642 & 1494 & 1361 & 1541 & 1487 \\
\hline Hainan & 34 & 37 & 91 & 82 & 84 & 75 & 100 & 78 \\
\hline Guangxi & 484 & 439 & 970 & 674 & 467 & 406 & 706 & 643 \\
\hline Chongqing & 249 & 270 & 1307 & 1037 & 367 & 388 & 317 & 353 \\
\hline Sichuan & 771 & 764 & 1560 & 1415 & 747 & 747 & 1112 & 1093 \\
\hline Guizhou & 424 & 318 & 1841 & 812 & 545 & 302 & 346 & 313 \\
\hline Yunnan & 383 & 322 & 837 & 628 & 551 & 410 & 462 & 461 \\
\hline Shaanxi & 352 & 281 & 1680 & 858 & 555 & 450 & 521 & 423 \\
\hline Gansu & 218 & 197 & 414 & 352 & 370 & 274 & 329 & 287 \\
\hline Qinghai & 58 & 48 & 77 & 101 & 92 & 103 & 68 & 70 \\
\hline Ningxia & 83 & 74 & 519 & 303 & 242 & 167 & 95 & 104 \\
\hline Xinjiang & 214 & 206 & 473 & 447 & 479 & 405 & 445 & 307 \\
\hline Inner Mongolia & 436 & 282 & 1386 & 570 & 1182 & 448 & 541 & 384 \\
\hline
\end{tabular}

Pro $=$ production-based emissions; Con $=$ consumption-based emissions .

China had the highest emission intensity for primary $\quad \mathrm{PM}_{2.5} \quad\left(50 \mathrm{Mg} 100\right.$ million $\left.\mathrm{CNy}^{-1}\right)$. In contrast, the least emission intensity occurred on the south coast $\left(39 \mathrm{Mg} 100\right.$ million $\mathrm{CNy}^{-1}$ for $\mathrm{SO}_{2}$ (49 $\mathrm{Mg} 100$ million $\mathrm{CNy}^{-1}$ for $\mathrm{NO}_{x}$ ) and the BeijingTianjin (13 Mg 100 million $\mathrm{CNy}^{-1}$ for $\mathrm{PM}_{2.5}$ and $41 \mathrm{Mg} 100$ million $\mathrm{CNy}^{-1}$ for NMVOC). However, in terms of pollution transfer, affluent areas such as BeijingTianjin, the east coast and the south coast were net pollution importers because of their relatively advanced economic development and modernized production technologies (thus lesser pollution intensity). For example, primary $\mathrm{PM}_{2.5}$ emissions embodied in imports to the east coast were 4 times greater than those embodied in exports with the factors for $\mathrm{SO}_{2}, \mathrm{NO}_{x}$ and NMVOC at 3, 2 and 1.5, respectively. About $80 \%$ of the emissions embodied in the east coast's imports occurred in the north, central and northeast. In BeijingTianjin, pollutants embodied in imports exceeded those embodied in exports by factors of 4.5, 4, 3 and 2 for primary
$\mathrm{PM}_{2.5}, \mathrm{SO}_{2}, \mathrm{NO}_{x}$ and NMVOC, respectively. Furthermore, $46 \%$ of the primary $\mathrm{PM}_{2.5}, 27 \%$ of $\mathrm{SO}_{2}, 28 \%$ of $\mathrm{NO}_{x}$ and $24 \%$ of NMVOC embodied in Beijing-Tianjin's imports derived from the north (including Hebei and Shandong). In contrast, less economically developed areas in the north, central, northwest and southwest regions were net exporters, with large quantities of emissions outsourced by eastern and south coast regions.

\subsection{Emissions embodied in international trade flows}

Figure 5 presents emissions embodied in internationally traded products at provincial level. In keeping with China's role as the world's largest exporter, most provinces had a trade deficit in embodied emissions. Shandong was the largest exporter with $260 \mathrm{Gg}$ of primary $\mathrm{PM}_{2.5}, 833 \mathrm{Gg}$ of $\mathrm{SO}_{2}, 687 \mathrm{Gg}$ of $\mathrm{NO}_{x}$ and $470 \mathrm{Gg}$ of NMVOC embodied in international exports, accounting for $11-13 \%$ of total emis- 


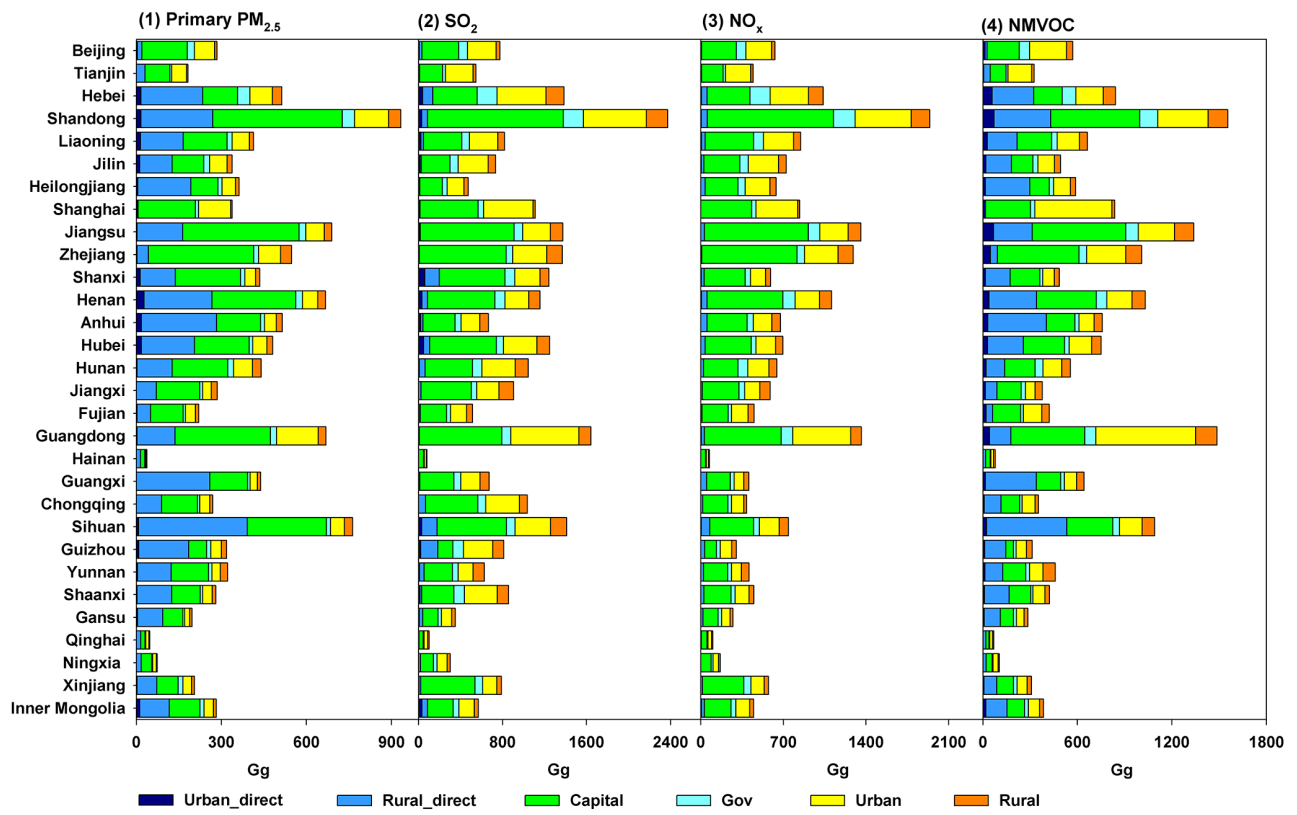

Figure 2. Consumption-based emissions in 2007 by province and final demand categories.

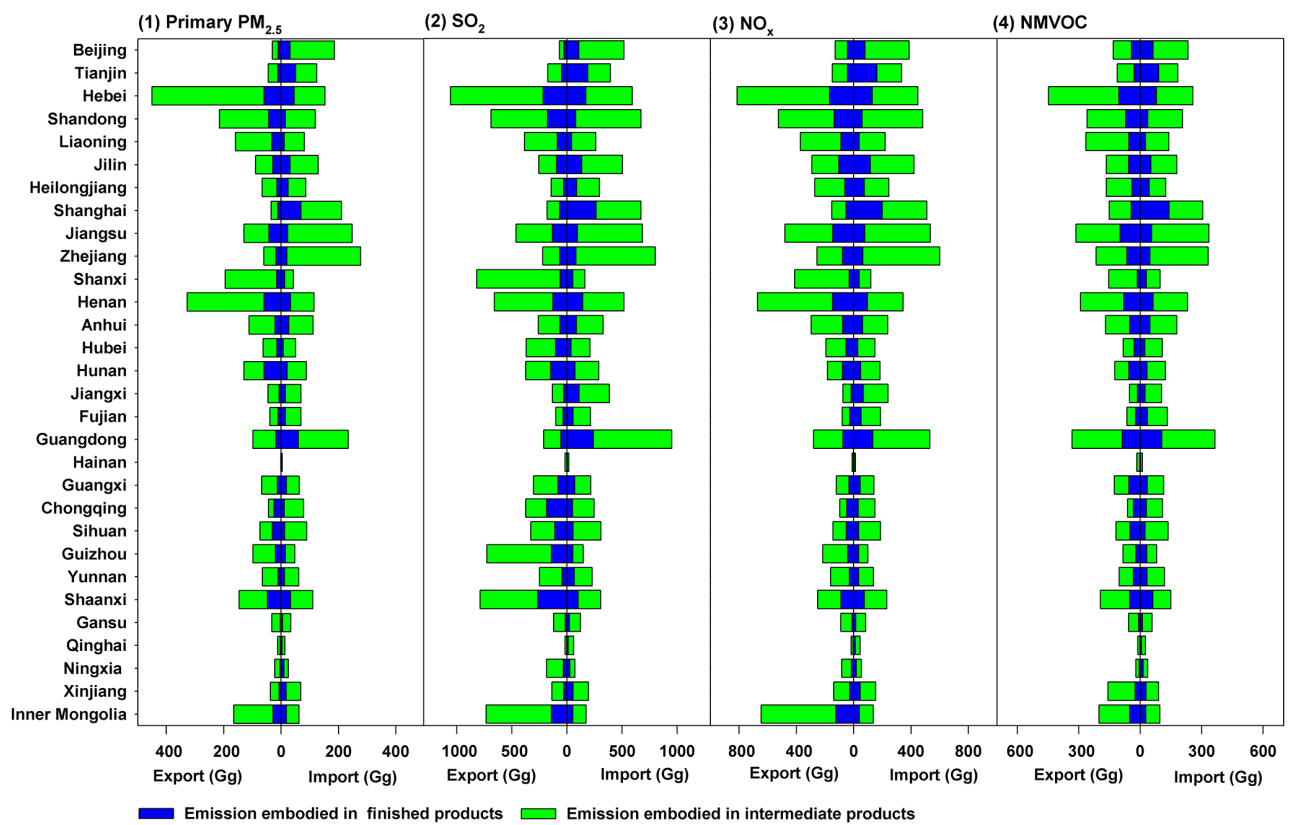

Figure 3. Balance of air pollutant emissions embodied in each province's interprovincial trade.

sions embodied in the country's international exports, followed by Guangdong, Hebei, Zhejiang and Jiangsu.

A province may make a final product for international export, but it can also make an intermediate product for another province's international export. The former process leads to emissions embodied in direct international export, whereas the latter leads to emissions associated with other regions' international export. International exports from the coastal areas (Guangdong, Fujian, Shanghai, Zhejiang, Jiangsu, Tian- jin and Shandong) accounted for $82 \%$ of all Chinese exports. However, the associated embodied emissions were only 43, 41,52 and $60 \%$ of national total export-embodied emissions for primary $\mathrm{PM}_{2.5}, \mathrm{SO}_{2}, \mathrm{NO}_{x}$ and NMVOC, respectively. Figure 6 presents the greatest cross-regional flows of emissions embodied in intermediate products caused by east coast regions' international export, which can explain the differences. We found that in coastal regions, $\sim 50 \%$ of emissions embodied in international trade were transferred to the cen- 


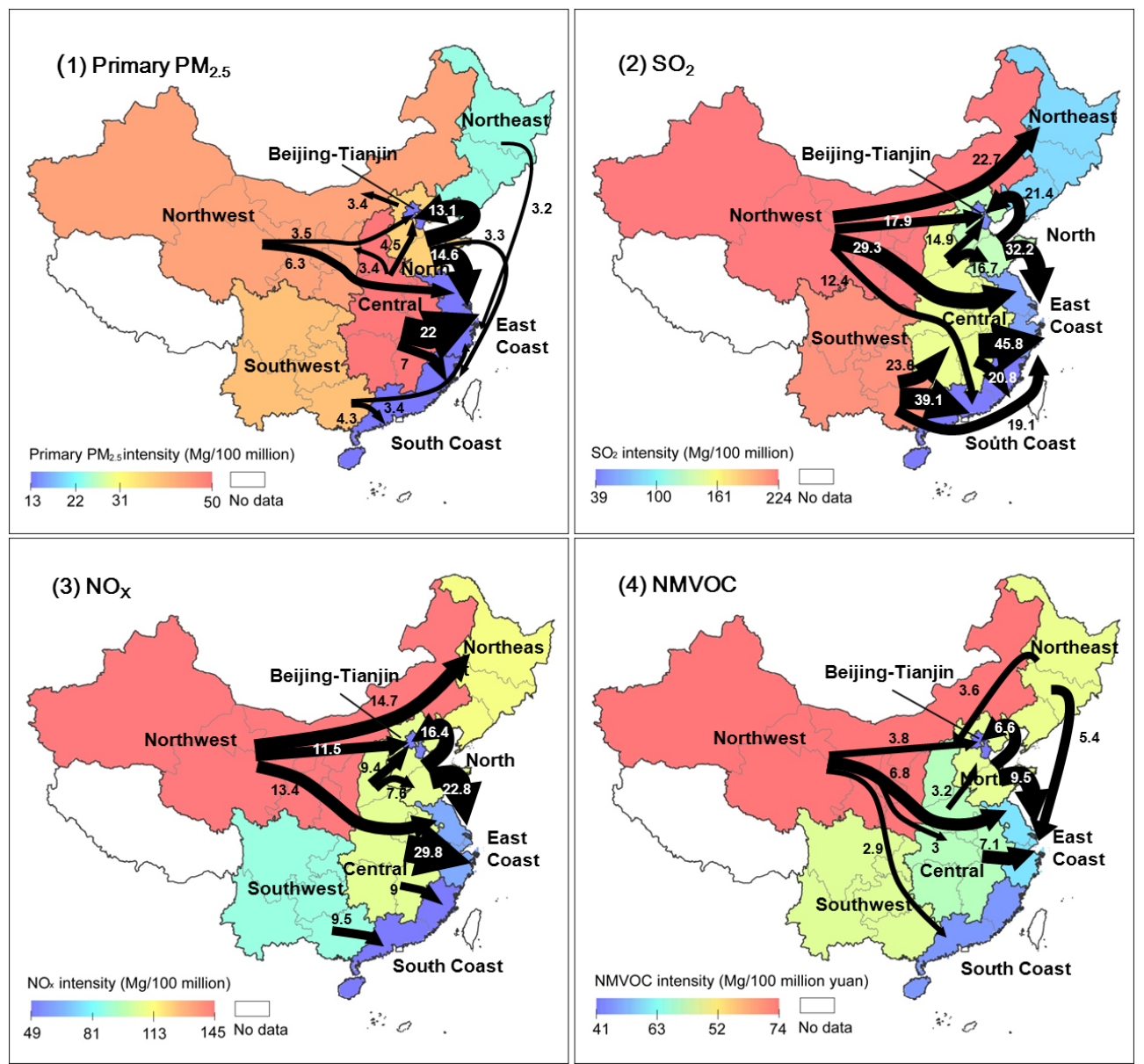

Figure 4. Largest net flows of primary $\mathrm{PM}_{2.5}, \mathrm{SO}_{2}, \mathrm{NO}_{x}$ and $\mathrm{NMVOC}$ emissions embodied in interprovincial trade in 2007 (unit of flow: $\mathrm{Gg}$ ). The shading in each region indicates the related production emission intensity.

tral, northwest and southwest through intermediate products to thus support their production export.

We estimated that $2.0 \mathrm{Tg}$ of primary $\mathrm{PM}_{2.5}(15 \%$ of total Chinese production-based emission), 7.0 Tg of $\mathrm{SO}_{2}$ $(21 \%), 5.7 \mathrm{Tg}$ of $\mathrm{NO}_{x}(23 \%)$ and $4.3 \mathrm{Tg}$ of NMVOC $(21 \%)$ were embodied in goods or services exported internationally, which are smaller than the estimates in Lin et al. (2014). Differences between that work and ours are mainly attributed to differences of method. Lin et al. (2014) used a single-region input-output (SRIO) model for China, whereas this research used a MRIO model framework. The SRIO uses national average emission intensity when calculating export embodied emissions, which would overestimate emissions in coastal provinces where emission intensities are less than the national average. In the MRIO framework, embodied emissions were calculated for each province using its own emission intensity. Thus estimates in Lin et al. (2014) would be greater than ours, because export volumes are dominated by coastal provinces.

\section{Policy implications}

\subsection{Impact from infrastructure construction}

Emissions related to construction-dominated capital formation accounted for $50 \%$ of all China's consumption-based emissions of air pollutants, corresponding to the increasing national urbanization rate from $26 \%$ in 1990 to $53 \%$ in 2013 (National Bureau of Statistics, 2014). This rapid urbanization has created a boom in demand for materials and infrastructure, thereby greatly accelerating industrial production and infrastructure construction and related pollutant emissions (Heinonen and Junnila, 2011). In addition, short-lived buildings aggravate this phenomenon; in China the average building life span of building is 35 years, much less than the 74 years in the United States and 132 years in the United Kingdom (China Economic Review, 2013).

Recent studies have shown that China's current technology improvements will barely be able to offset pollutant emissions associated with increasing consumption (Liang et al., 2014; Guan et al., 2014b). However, the national govern- 


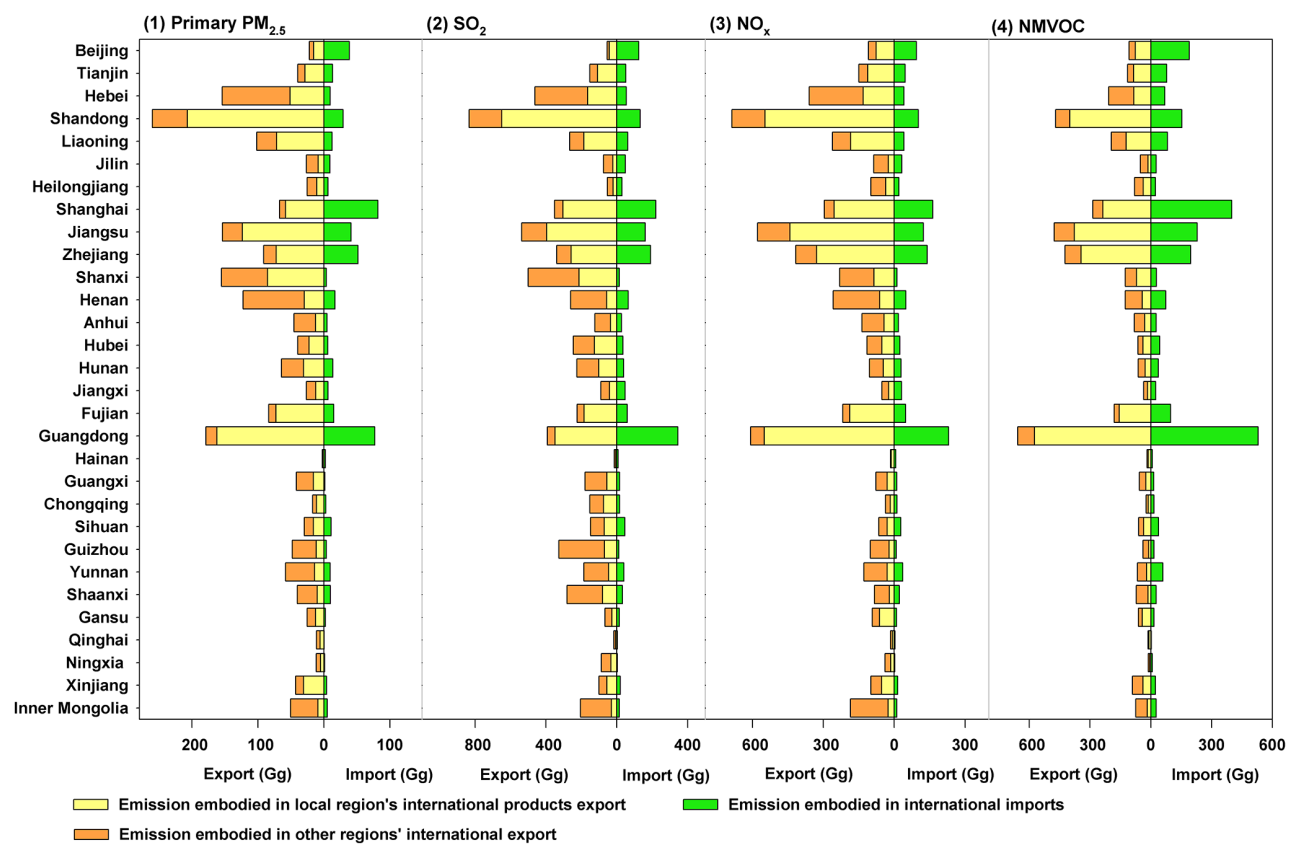

Figure 5. Balance of pollutant emissions embodied in each province's international trade.

ment must continue to promote economic growth to improve livelihoods and overcome environmental problems. Thus, to achieve pollution reduction targets, the government should focus on key source sectors and technologies but must also give greater attention to control and management strategies regarding consumption. Our study indicates that key regulatory policies should focus on the construction sector, such as promoting the use of energy-saving building materials and increasing building life spans, thereby reducing related upstream emissions along supply chains. Given the increasing consumption, advocating conservation behaviors in daily life is also essential. To encourage rational spending, suitable tax policy can be used to transfer environmental impacts to consumers, thus reducing the consumption volume and related emissions.

\subsection{Importance of interprovincial and international transfer in pollutants}

Interprovincial trade in China is accompanied by substantial pollutant transfer. As shown in Fig. 3, 23, 33, 31 and $23 \%\left(3.1,10.5,7.6\right.$ and $4.7 \mathrm{Tg}$ ) of China's primary $\mathrm{PM}_{2.5}$, $\mathrm{SO}_{2}, \mathrm{NO}_{x}$ and $\mathrm{NMVOC}$, respectively, are related to goods or services that are ultimately consumed outside the provinces where they were produced. Most of this pollutant transfer is between developing central and western regions and the affluent east coastal regions.

Recently, the central government has launched nationwide acts to reduce $\mathrm{CO}_{2}$ emission (Liu et al., 2012b) and atmospheric pollutants (The State Council of the PRC, 2013), with stricter measures for eastern provinces than western ones.
This disparity in mitigation targets is likely to accelerate the relocation of heavy industries to less-developed central and western regions, thereby worsening the atmospheric environment there. Figure 4 reveals that production-related pollution intensities of the eight regions had gradually increasing trends from the developed southeast to less-developed northwest regions. This means that more pollutants were emitted to make one product unit in the central and west regions. Relocating industries will therefore redistribute the environmental problem rather than eliminate it, which is known as the "beggar-thy-neighbor" effect. Furthermore, increasing interprovincial trade will also drive traffic flows, which have been a key contributor to atmospheric pollutant emissions (Cheng et al., 2013). Consequently, this kind of industrial shift may ultimately increase total national pollutant emissions.

As air pollutants can be transported over a great distance in the atmosphere (Lin et al., 2014), outsourced emissions in developing provinces may blow back to the developed provinces under certain meteorological conditions (Ying et al., 2014). Hence, an effective regional pollution control strategy should target reduction of total emissions rather than simply relocating them. To alleviate this problem, technology transfer between developed and developing regions should play a leading role in joint actions for regional or interregional air pollution control. In addition, for developed regions, industrial transfer should be accompanied by technology transfer; for less-developed regions, a stricter emission standard should be established for new installations that exceed a given benchmark, thereby reducing the increment of emissions. 

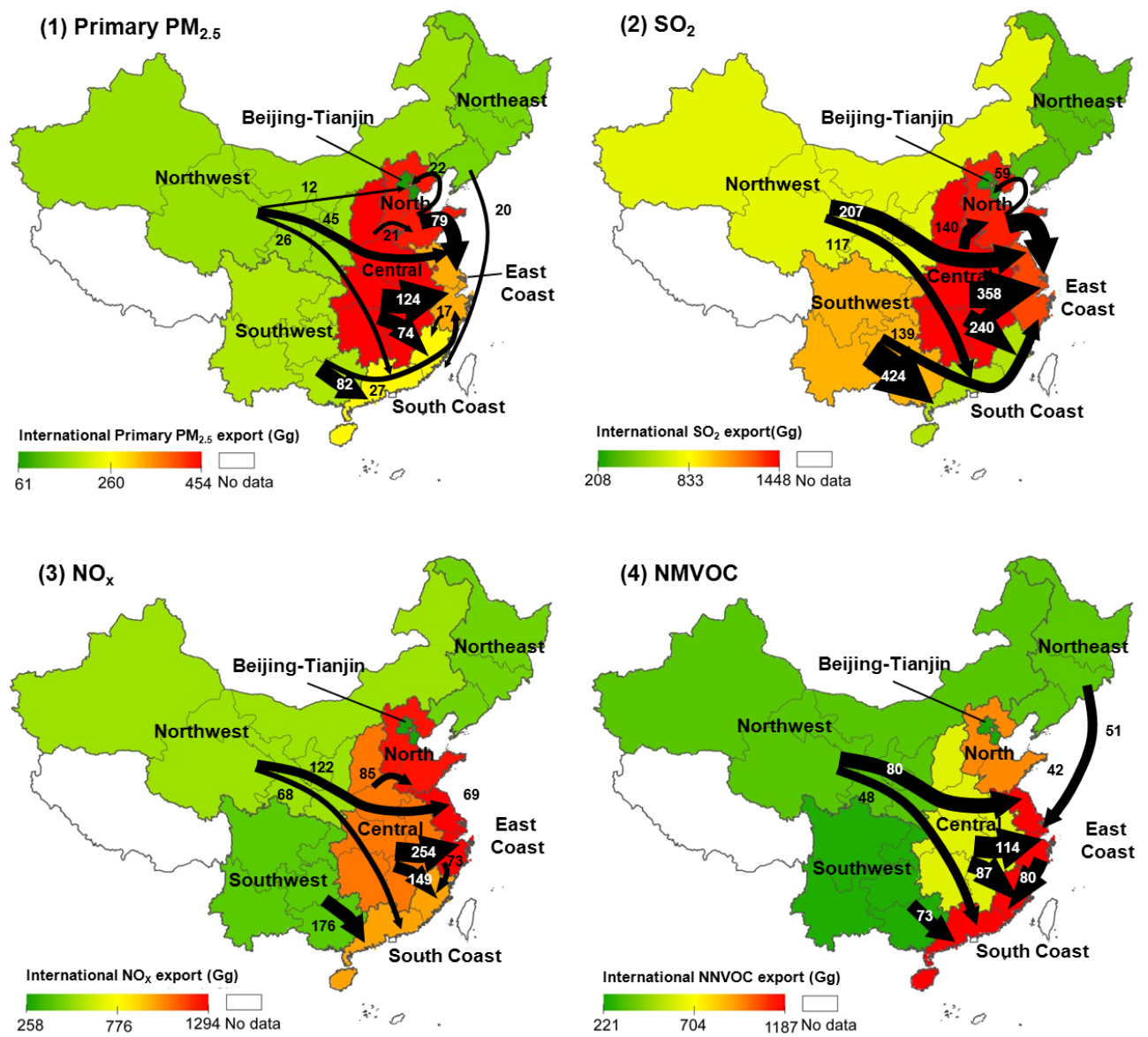

Figure 6. Regional pollutant emissions due to production of intermediate products to support other regions' international exports (unit of flow: $\mathrm{Gg}$ ). The shading from green to red indicates each region's total international pollutant exports.

Economic mechanisms could also provide alternative means by involving both producers and consumers in emissions mitigation. The pilot phase of China's Emissions Trading Scheme (ETS) on $\mathrm{CO}_{2}, \mathrm{SO}_{2}$ and $\mathrm{NO}_{x}$ has proven its effectiveness in emission reductions. Thus expanding the ETS system nationwide can be used to mitigate emissions. Economic stimuli or penalties instigated by leading companies could reduce the emissions of their suppliers more effectively as companies are the agents that decide to outsource their production chains (O'Rourke, 2014) and thus can exert a cleaning effect on its upstream supply chains (Skelton, 2013). An eco-labeling system could achieve efficiency gains by producers which can be monitored by regulative bodies. Consumer choice in eco-labeling could be a great incentive for companies to adopt such a scheme to promote market competitiveness (Grundey and Zaharia, 2008).

The present results also indicated that substantial leakage of emissions from foreign countries to China via international trade. Pollution embodied in that trade accounted for $15-23 \%$ of total pollutant emission in China. Furthermore, $41-60 \%$ of the embodied emissions occurred in Tianjin, Shandong, Jiangsu, Shanghai, Zhejiang, Fujian and Guang- dong, all of which are within the country's three largest industrial bases (Jing-Jin-Ji, Yangtze River Delta and Pearl River Delta) where air pollution is severe. Thus, reduction policies related to export adjustment should concentrate on these key export-oriented regions and on exported products involving multi-sector and multiregional supply chains with little added value (Skelton et al., 2011; Skelton, 2013).

\section{Concluding remarks}

In this work, we used an MRIO framework to estimate consumption-based air pollutant emissions for China in the year 2007 at the provincial level. This is the first time that virtual air pollutant emissions embodied in interprovincial trade were quantified and tracked. We found that coastal provinces outsourced large quantities of emissions to inland provinces through import of goods. Emissions were significantly redistributed owing to interprovincial trade. Future work can link our provincial level consumption-based inventory and pollution flows with chemical transport models to investigate the impacts of trade activities on regional and global air quality. 
Our MRIO analysis traced pollutant sources related to consumption activities. It clearly illustrated the extent and structure of pollutant externalization and presented a reasonable approach to facilitating collaboration between producers and consumers. This approach appears an effective means to optimize air quality management decisions toward environmentally sustainable economic growth. The results of the work may help policy makers better understand the responsibility for pollution from a consumption perspective. However, partitioning responsibility between producers and consumers is more complicated, because producers accrue economic benefit when emitting pollutants (Barrett et al., 2013). Reasonable shared responsibility criteria (e.g., Gallego and Lenzen, 2005; Lenzen et al., 2007; Cadarso et al., 2012; Hoekstra and Wiedmann, 2014) involving both producers and consumers in emission reduction could help developing provinces in China assume the cost increase derived from mitigation action and contribute to a more effective solution. 


\section{Appendix A}

Table A1. Sectors classification for MRIO Table.

\begin{aligned} & \hline Sector number Sector name \\ & \hline 1 Agriculture \\ & 2 Coal mining and processing \\ & 3 Crude petroleum and natural gas products \\ & 4 Metal ore mining \\ & 5 Non-ferrous mineral mining \\ & 6 Manufacture of food products and tobacco processing \\ & 7 Textile goods \\ & 8 Wearing apparel, leather, furs, down and related products \\ & 9 Sawmills and furniture \\ & 10 Paper and products, printing and record medium reproduction \\ & 11 Petroleum processing and coking \\ & 12 Chemicals \\ & 13 Nonmetal mineral products \\ & 14 Metals smelting and pressing \\ & 15 Metal products \\ & 16 Machinery and equipment \\ & 17 Transport equipment \\ & 18 Electric equipment and machinery \\ & 19 Electronic and telecommunication equipment \\ & 20 Instruments, meters, cultural and office machinery \\ & 21 Handicrafts and other manufacturing \\ & 22 Electricity, steam and hot water production and supply \\ & 23 Gas and water production and supply \\ & 24 Construction \\ & 25 Transport and warehousing, post and telecommunication \\ & 26 Wholesale and retail and catering accommodation \\ & 27 Others \\ & \hline \\ & \hline\end{aligned}

Table A2. Region divisions.

\begin{tabular}{ll}
\hline Region & Provinces/municipalities that included in each region \\
\hline Beijing-Tianjin & Beijing and Tianjin \\
North & Hebei and Shandong \\
Northeast & Liaoning, Jilin and Heilongjiang \\
East coast & Jiangsu, Shanghai and Zhejiang \\
Central & Shanxi, Henan, Anhui, Hunan, Hubei and Jiangxi \\
South coast & Fujian, Guangdong and Hainan \\
Southwest & Sichuan, Chongqing, Guizhou, Yunnan, Guangxi (and Tibet) \\
Northwest & Shaanxi, Gansu, Qinghai, Ningxia, Xinjiang and Inner Mongolia \\
\hline
\end{tabular}


Acknowledgements. This study was supported by China's National Basic Research Program (2014CB441301) and the National Science Foundation of China (41222036, 71322304, 41328008, 41175127, 41422502 and 71341025). Q. Zhang and K. B. He are supported by the Collaborative Innovation Center for Regional Environmental Quality. We thank the three anonymous reviewers for their constructive comments.

Edited by: Y. Cheng

\section{References}

Barrett, J., Peters, G., Wiedmann, T., Scott, K., Lenzen, M., Roelich, K., and Le Quéré, C.: Consumption-based GHG emission accounting: a UK case study, Clim. Policy, 13, 451-470, doi:10.1080/14693062.2013.788858, 2013.

Bell, M. L., Dominici, F., Ebisu, K., Zeger, S. L., and Samet, J. M.: Spatial and temporal variation in $\mathrm{PM}_{2.5}$ chemical composition in the United States for health effects studies, Environ. Health Persp., 115, 989-995, doi:10.1289/ehp.9621, 2007.

Boldo, E., Medina, S., Le Tertre, A., Hurley, F., Mücke, H.-G., Ballester, F., and Aguilera, I.: Apheis: Health impact assessment of long-term exposure to PM2. 5 in 23 European cities, Eur. J. Epidemiol, 21, 449-458, 2006.

Cadarso, M.-Á., López, L.-A., Gómez, N., and Tobarra, M.-Á.: International trade and shared environmental responsibility by sector. An application to the Spanish economy, Ecol. Econ., 83, 221-235, doi:10.1016/j.ecolecon.2012.05.009, 2012.

Cheng, S., Lang, J., Zhou, Y., Han, L., Wang, G., and Chen, D.: A new monitoring-simulation-source apportionment approach for investigating the vehicular emission contribution to the $\mathrm{PM}_{2.5}$ pollution in Beijing, China, Atmos. Environ., 79, 308-316, doi:10.1016/j.atmosenv.2013.06.043, 2013.

China Economic Review: How will a slowing China cope with rapidly aging buildings?, available at: http: //www.chinaeconomicreview.com/Unstable-Foundations-Part-2 (last access: 28 June 2013), 2014.

Davis, S. J. and Caldeira, K.: Consumption-based accounting of $\mathrm{CO}_{2}$ emissions, P. Natl. Acad. Sci. USA, 107, 5687-5692, 2010.

Davis, S. J., Peters, G. P., and Caldeira, K.: The supply chain of $\mathrm{CO}_{2}$ emissions, P. Natl. Acad. Sci. USA, 108, 18554-18559, 2011.

Feng, K., Siu, Y. L., Guan, D., and Hubacek, K.: Analyzing Drivers of Regional Carbon Dioxide Emissions for China, J. Ind. Ecol., 16, 600-611, doi:10.1111/j.1530-9290.2012.00494.x, 2012.

Feng, K., Davis, S. J., Sun, L., Li, X., Guan, D., Liu, W., Liu, Z., and Hubacek, K.: Outsourcing $\mathrm{CO}_{2}$ within China, P. Natl. Acad. Sci. USA, 110, 11654-11659, doi:10.1073/pnas.1219918110, 2013.

Gallego, B. and Lenzen, M.: A consistent input-output formulation of shared producer and consumer responsibility, Econ. Syst. Res., 17, 365-391, doi:10.1080/09535310500283492, 2005.

Grundey, D. and Zaharia, R. M.: Sustainable incentives in marketing and strategic greening: The cases of Lithuania and Romania, Ukio Technologinis ir Ekonominis Vystymas, 14, 130-143, doi:10.3846/1392-8619.2008.14.130-143, 2008.

Guan, D. and Barker, T.: Low-carbon development in the least developed region: a case study of Guangyuan, Sichuan province, southwest China, Nat. Hazards, 62, 243-254, doi:10.1007/s11069-011-9993-3, 2012.
Guan, D., Lin, J., Davis, S. J., Pan, D., He, K., Wang, C., Wuebbles, D. J., Streets, D. G., and Zhang, Q.: Reply to Lopez et al.: Consumption-based accounting helps mitigate global air pollution, P. Natl. Acad. Sci. USA, 111, E2631, doi:10.1073/pnas.1407383111, 2014a.

Guan, D., Hubacek, K., Tillotson, M., Zhao, H., Liu, W., Liu, Z., and Liang, S.: Lifting China's Water Spell, Environ. Sci. Technol., 48, 11048-11056, doi:10.1021/es501379n, 2014b.

Guan, D., Su, X., Zhang, Q., Peters, G. P., Liu, Z., Lei, Y., and He, K.: The socioeconomic drivers of China's primary $\mathrm{PM}_{2.5}$ emissions, Environ. Res. Lett., 9, 024010, doi:10.1088/17489326/9/2/024010, 2014c.

Heinonen, J. and Junnila, S.: A carbon consumption comparison of rural and urban lifestyles, Sustainability, 3, 1234-1249, 2011.

Hertwich, E. G. and Peters, G. P.: Carbon footprint of nations: A global, trade-linked analysis, Environ. Sci. Technol., 43, 64146420, 2009.

Hoekstra, A. Y. and Wiedmann, T. O.: Humanity's unsustainable environmental footprint, Science, 344, 1114-1117, doi:10.1126/science.1248365, 2014.

Hubacek, K. and Sun, L.: Economic and Societal Changes in China and their Effects on Water Use A Scenario Analysis, J. Ind. Ecol., 9, 187-200, 2005.

Lei, Y., Zhang, Q., He, K. B., and Streets, D. G.: Primary anthropogenic aerosol emission trends for China, 1990-2005, Atmos. Chem. Phys., 11, 931-954, doi:10.5194/acp-11-931-2011, 2011.

Lenzen, M., Murray, J., Sack, F., and Wiedmann, T.: Shared producer and consumer responsibility - Theory and practice, Ecol. Econ., 61, 27-42, doi:10.1016/j.ecolecon.2006.05.018, 2007.

Lenzen, M., Kanemoto, K., Moran, D., and Geschke, A.: Mapping the structure of the world economy, Environ. Sci. Technol., 46, 8374-8381, 2012.

Lenzen, M., Moran, D., Kanemoto, K., and Geschke, A.: Building EORA: A global multi-region input-output database at high country and sector resolution, Econ. Syst. Res., 25, 20-49, 2013.

Leontief, W.: Environmental repercussions and the economic structure: an input-output approach, Rev. Econ. Statistics, 52, 262 271, 1970.

Liang, S., Liu, Z., Crawford-Brown, D., Wang, Y., and Xu, M.: Decoupling analysis and socioeconomic drivers of environmental pressure in China, Environ. Sci. Technol., 48, 1103-1113, doi:10.1021/es4042429, 2014.

Lin, J., Nielsen, C. P., Zhao, Y., Lei, Y., Liu, Y., and McElroy, M. B.: Recent changes in particulate air pollution over China observed from space and the ground: effectiveness of emission control, Environ. Sci. Technol., 44, 7771-7776, 2010.

Lin, J., Pan, D., Davis, S. J., Zhang, Q., He, K., Wang, C., Streets, D. G., Wuebbles, D. J., and Guan, D.: China's international trade and air pollution in the United States, P. Natl. Acad. Sci. USA, 44, 7771-7776, doi:10.1021/es101094t, 2014.

Lindner, S., Liu, Z., Guan, D., Geng, Y., and Li, X.: $\mathrm{CO}_{2}$ emissions from China's power sector at the provincial level: Consumption versus production perspectives, Renew. Sust. Energ. Rev., 19, 164-172, doi:10.1016/j.rser.2012.10.050, 2013.

Lindner, S. and Guan, D.: A Hybrid-Unit Energy Input-Output Model to Evaluate Embodied Energy and Life Cycle Emissions for China's Economy, J. Ind. Ecol., 18, 201-211, doi:10.1111/jiec.12119, 2014. 
Liu, W., Chen, J., Tang, Z., Liu, H., Han, D., and Li, F.: Prepared Theory and Practice multi-regional input-output tables for 30 region in China in 2007, China Statistics Press, Beijing, 2012 (in Chinese).

Liu, Z., Liang, S., Geng, Y., Xue, B., Xi, F., Pan, Y., Zhang, T., and Fujita, T.: Features, trajectories and driving forces for energyrelated GHG emissions from Chinese mega cites: The case of Beijing, Tianjin, Shanghai and Chongqing, Energy, 37, 245-254, 2012a.

Liu, Z., Geng, Y., Lindner, S., and Guan, D.: Uncovering China's greenhouse gas emission from regional and sectoral perspectives, Energy, 45, 1059-1068, doi:10.1016/j.energy.2012.06.007, 2012 b.

Liu, Z., Guan, D., Crawford-Brown, D., Zhang, Q., He, K., and Liu, J.: A low-carbon road map for China, Nature, 500, 143-145, 2013.

López, L.-A., Arce, G., and Zafrilla, J.: Financial Crisis, Virtual Carbon in Global Value Chains, and the Importance of Linkage Effects. The Spain-China Case, Environ. Sci. Technol., 48, 3644, doi:10.1021/es403708m, 2014.

Minx, J., Wiedmann, T., Wood, R., Peters, G. P., Lenzen, M., Owen, A., Scott, K., Barrett, J., Hubacek, K., and Baiocchi, G.: Inputoutput analysis and carbon footprinting: an overview of applications, Econ. Syst. Res., 21, 187-216, 2009.

National Bureau of Statistics: China Foreign Economic Statistical Yearbook, China Stat. Press Beijing, 2008a.

National Bureau of Statistics: China Trade and Economic Statistical Yearbook, China Stat. Press, Beijing, 2008b.

National Bureau of Statistics: China Energy Statistical Yearbook, China Stat. Press, Beijing, 2008c.

National Bureau of Statistics: China Economic Census Yearbook, China Stat. Press, Beijing, 2010.

National Bureau of Statistics: China Region input-output tables China Stat. Press, Beijing, 2011.

National Bureau of Statistics: China Region input-output tables China Stat. Press, Beijing, 2014.

Ohara, T., Akimoto, H., Kurokawa, J., Horii, N., Yamaji, K., Yan, X., and Hayasaka, T.: An Asian emission inventory of anthropogenic emission sources for the period 1980-2020, Atmos. Chem. Phys., 7, 4419-4444, doi:10.5194/acp-7-4419-2007, 2007.

O'Rourke, D.: The science of sustainable supply chains, Science, 344, 1124-1127, doi:10.1126/science.1248526, 2014.

Peters, G. P.: From production-based to consumption-based national emission inventories, Ecol. Econ., 65, 13-23, 2008.

Peters, G. P. and Hertwich, E. G.: Post-Kyoto greenhouse gas inventories: production versus consumption, Clim. Change, 86, 51-66, 2008.

Peters, G. P., Minx, J. C., Weber, C. L., and Edenhofer, O.: Growth in emission transfers via international trade from 1990 to 2008, P. Natl. Acad. Sci. USA, 108, 8903-8908, 2011.
Skelton, A.: EU corporate action as a driver for global emissions abatement: A structural analysis of EU international supply chain carbon dioxide emissions, Global Environ. Chang., 23, 17951806, doi:10.1016/j.gloenvcha.2013.07.024, 2013.

Skelton, A., Guan, D., Peters, G. P., and Crawford-Brown, D.: Mapping flows of embodied emissions in the global production system, Environ. Sci. Technol., 45, 10516-10523, 2011.

Streets, D., Bond, T., Carmichael, G., Fernandes, S., Fu, Q., He, D., Klimont, Z., Nelson, S., Tsai, N., and Wang, M. Q.: An inventory of gaseous and primary aerosol emissions in Asia in the year 2000, J. Geophys. Res., 108, 8809, doi:10.1029/2002JD003093, 2003.

Suh, S.: Handbook of Input-Output Economics in Industrial Ecology, Springer-Verlag, the Netherlands, 2009.

Tang, X., Zhang, B., Feng, L., Snowden, S., and Höök, M.: Net oil exports embodied in China's international trade: An input-output analysis, Energy, 48, 464-471, 2012.

The State Council of the PRC: Action Plan for Air Pollution Control, available at: http://www.gov.cn/zwgk/2013-09/12/content_ 2486773.htm (last access: June 2014), 2013.

Wiedmann, T.: A review of recent multi-region input-output models used for consumption-based emission and resource accounting, Ecol. Econ., 69, 211-222, 2009.

Wiedmann, T., Lenzen, M., Turner, K., and Barrett, J.: Examining the global environmental impact of regional consumption activities - Part 2: Review of input-output models for the assessment of environmental impacts embodied in trade, Ecol. Econ., 61, 1526, 2007.

Yang, G., Wang, Y., Zeng, Y., Gao, G. F., Liang, X., Zhou, M., Wan, X., Yu, S., Jiang, Y., and Naghavi, M.: Rapid health transition in China, 1990-2010: findings from the Global Burden of Disease Study 2010, Lancet, 381, 1987-2015, 2013.

Ying, Q., Wu, L., and Zhang, H.: Local and inter-regional contributions to $\mathrm{PM}_{2.5}$ nitrate and sulfate in China, Atmos. Environ., 94, 582-592, doi:10.1016/j.atmosenv.2014.05.078, 2014.

Yu, F., Ma, G., Zhang, Y., Cao, D., Gao, F., and Wang, J.: Several issues about health impact assessment of China's air pollution, Nat. Med. J. China, 93, 2695-2698, 2013 (in Chinese).

Zhang, Q., Streets, D. G., He, K., and Klimont, Z.: Major components of China's anthropogenic primary particulate emissions, Environ. Res. Lett., 2, 045027, doi:10.1088/17489326/2/045027, 2007.

Zhang, Q., Streets, D. G., Carmichael, G. R., He, K. B., Huo, H., Kannari, A., Klimont, Z., Park, I. S., Reddy, S., Fu, J. S., Chen, D., Duan, L., Lei, Y., Wang, L. T., and Yao, Z. L.: Asian emissions in 2006 for the NASA INTEX-B mission, Atmos. Chem. Phys., 9, 5131-5153, doi:10.5194/acp-9-5131-2009, 2009. 